\title{
Statistics and Analysis on the Study of Taboo in China Since the 21st Century
}

\author{
Wang Shuai, Kailibinu \\ Email address: \\ 1515532068@qq.com (Wang Shuai),377942403@qq.com (Kailibinu)
}

School of Uyghur Language and Literature, Northwest Minzu University, Lanzhou, China

To cite this article:

Wang Shuai, Kailibinu. Statistics and Analysis on the Study of Taboo in China Since the 21 st Century. Humanities and Social Sciences. Vol. 5, No. 2, 2017, pp. 108-112. doi: 10.11648/j.hss.20170502.20

Received: April 11, 2017; Accepted: May 18, 2017; Published: May 20, 2017

\begin{abstract}
Taboo is an inseparable part of the language and a universal social phenomenon, It plays an important role in language and social life. Since the 21 st century, there have been many papers on the study of taboo in China, so it is necessary to sort out the papers as a whole. This paper uses the method of statistics to analyze the qualitative and qualitative analysis of the published time, author, unit, subject and so on of the relevant papers, so as to understand the appearance of taboo research in China since the 21 st century and puts forward the prospect of future research on taboo.
\end{abstract}

Keywords: 21st Century, Taboo Research, Statistics, Analysis, Outlook

\section{Introduction}

In language communication, there are some words can not casually say, it may be caused by the listener's displeasure and disgust, which is linguistic said "taboo". Taboo is an integral part of the language, it plays an important role in the language. [1] Han nationality as an ancient nation, in the long process of development to form their own unique national culture. One of the salient features of the Han culture is to pay attention to civilization, to be subtle, so people are scruples in the conversation, to avoid the use of those with traditional or social customs do not match the language, that is taboo. So the taboo language in the Chinese language is a pivotal position. [2]

Due to the prominent status of taboo, so the study of taboo language has always been a hot topic of language research. Since the 21 st century, there have been many papers on the study of taboo in China, so it is necessary to sort out the papers in this paper as a whole. This paper uses the method of statistical analysis to analyze the qualitative and qualitative analysis of the published literature, the author's time, author, the unit, the subject and so on, so as to comprehensively understand the 21 st century The face of taboo research in our country.

Taboo as part of the human language is a common cultural phenomenon of all ethnic groups in life is inevitable. With the development of social culture and the increasingly frequent intercultural communication activities, the literature statistics of these literatures can be pointed out. It can be pointed out that the direction, problems and suggestions of taboo research are of great significance to the new development and new trend of taboo.

\section{Data Sources}

The data comes from the core resources "China Knowledge Resource Library" of CNKI .

"China Knowledge Resource Library" of CNKI is China's knowledge and information resources of large-scale integration, which is very rich in various types of resources. [3] Since the $21 \mathrm{st}$ century, China's literature on taboo research can basically be found in the paper. This paper chooses the journal papers, dissertations and conference papers published in 2001 to 2016, and then analyzes, summarizes and classifies the valid data.

In "China Knowledge Resource Library" of CNKI, you can search for 392 papers of taboo published in 2001 to 2015. There are 387 articles that exclude duplicate papers and irrelevant papers. This article will be the 387 papers as the object of study. 


\section{A Statistical Analysis of the Time of Publication}

Table 1. Time and quantity statistics published in the paper.

\begin{tabular}{lll}
\hline Year & Number & proportion \\
\hline 2001 & 7 & $1.81 \%$ \\
2002 & 7 & $1.81 \%$ \\
2003 & 8 & $2.07 \%$ \\
2004 & 13 & $3.36 \%$ \\
2005 & 16 & $4.13 \%$ \\
2006 & 28 & $7.24 \%$ \\
2007 & 34 & $8.79 \%$ \\
2008 & 40 & $10.34 \%$ \\
2009 & 31 & $8.01 \%$ \\
2010 & 27 & $6.98 \%$ \\
2011 & 39 & $10.08 \%$ \\
2012 & 38 & $9.82 \%$ \\
2013 & 40 & $10.34 \%$ \\
2014 & 36 & $9.30 \%$ \\
2015 & 23 & $5.94 \%$ \\
Total & 387 & $100.00 \%$ \\
\hline
\end{tabular}

As can be seen from Table 1, the research paper on the taboo of our country has shown a tendency to rise first and foremost since the 21 st century: the rapid growth of the ban on language research from 2001 to 2008 is increasing year by year, and Increase significantly; 2008 to 2015 reached the highest value of 40, and although the ups and downs in recent years, but the overall remained stable, with an average of 35 or so.

From 2001 to 2008, the rapid growth of prohibitions on the study of taboo language shows that the study of taboos has been paid attention by academics and scholars. The highest value has been reached between 2008 and 2015, and the amount of literature has remained at about 35 , indicating that The number of papers studied in the paper to a relatively stable horizontal finishing stage, indicating that the field of research has been the common concern of academic colleagues, research heat continued to be stable.

Which shows a downward trend from 2013 to 2015, and the decline from 2014 to 2015 is obvious, although the time span is slightly smaller, but it may be that China's research on taboo is more comprehensive and thorough, not too many innovative point of view, So the current study on the taboo of the heat is weakening.ion mark.

\section{A Statistical Analysis of the Forms of Documents}

According to the type of 387 papers, we can see that the extracted papers are journal articles, dissertations, conference papers and newspaper articles. The distribution is shown in Table 2.
Table 2. Source of the paper.

\begin{tabular}{lll}
\hline Source & Number & proportion \\
\hline Papers & 329 & $85.01 \%$ \\
Thesis & 51 & $13.18 \%$ \\
Proceedings & 6 & $1.55 \%$ \\
Newspaper articles & 1 & $0.26 \%$ \\
Collection & 387 & $100.00 \%$ \\
\hline
\end{tabular}

Among them, 329 journal articles were published in 223 journals, including 155 journal articles published in university journals, accounting for $47.11 \%$ of all journals. The top ten journals of the relevant papers are shown in Table 3.

Table 3. The top ten journals of the journal.

\begin{tabular}{ll}
\hline Journal title & Number \\
\hline Test Weekly & 15 \\
Journal of Chinese Language & 7 \\
Overseas English & 6 \\
Journal of Hotan Teachers College & 6 \\
Technology information & 6 \\
Anhui literature & 5 \\
Talented & 5 \\
Film literature & 5 \\
Read and write & 5 \\
Journal of Qiqihar University & 5 \\
\hline
\end{tabular}

In addition, in the 51 degree thesis, more with the taboo-related research as a dissertation topic of colleges and universities as shown in Table 4.

Table 4. The first eleven college statistics of the topic selection thesis.

\begin{tabular}{ll}
\hline Name of university & Number \\
\hline Jilin University & 5 \\
Shan Dong University & 3 \\
Chengdu University of Technology & 2 \\
Fudan University & 2 \\
Guangxi University for Nationalities & 2 \\
Heilongjiang University & 2 \\
Qufu Normal University & 2 \\
Shandong Normal University & 2 \\
Suzhou University & 2 \\
Wuhan University of Technology & 2 \\
Yanbian University & 2 \\
\hline
\end{tabular}

\section{A Statistical Analysis of the Authors}

The author of this 387 paper analysis and statistics, according to the amount of hair sorting statistics out of the distribution of the author. This article lists the core of the two authors and the author, see Table 5.

According to Price theory, the formula for calculating the core author is: $\mathrm{m}=0.749 \sqrt{\mathrm{n}_{\max }}$ (where the author is the author of the most text, $n_{\max }$ is the lowest author of the core). [4] From the table 5 to get the most text of the author of the amount of 6 , calculated $m \approx 1.84$, which can be defined as two as the core of the author, the statistics obtained by the core of the nine, and most of the author's unit For institutions of higher learning. This shows that our researchers have a certain number of core writers on the study of taboo language, and by the university scholars generally concerned. [5] 
Table 5. To the taboo language as the object of the author of the issue of the order.

\begin{tabular}{|c|c|c|}
\hline Name & Unit & Number \\
\hline Fu Jie & $\begin{array}{l}\text { Foreign Languages Institute of Bohai } \\
\text { University }\end{array}$ & 6 \\
\hline Liu Baiyu & $\begin{array}{l}\text { School of Foreign Languages, Shandong } \\
\text { Institute of Business and Technology }\end{array}$ & 4 \\
\hline Zhou Xiumin & $\begin{array}{l}\text { College of Foreign Languages, Henan } \\
\text { Agricultural University }\end{array}$ & 3 \\
\hline Lei Qin & Quzhou College of Foreign Languages & 3 \\
\hline Xu Ying & Yanbian University & 2 \\
\hline Ma Shilin & $\begin{array}{l}\text { College of Foreign Languages, Changshu } \\
\text { College }\end{array}$ & 2 \\
\hline Liu Min & $\begin{array}{l}\text { School of Foreign Languages, Shaanxi } \\
\text { Institute of Technology }\end{array}$ & 2 \\
\hline Li Yuling & Tongji University & 2 \\
\hline Du Yajing & $\begin{array}{l}\text { Wuchang Institute of Technology Grammar } \\
\text { and Foreign Languages Institute }\end{array}$ & 2 \\
\hline
\end{tabular}

In addition, it is clear from the units of the researchers listed in Table 5 that most of them belong to the foreign language system. This shows that since the 21 st century, Chinese scholars have focused on the taboo of foreign languages and the comparison of Chinese and foreign language taboos. [6] This change has been closely related to the study of taboo in Chinese before the 21 st century.

\section{A Statistical Analysis of Cited Number of Papers}

By analyzing the number of citations of 387 papers, the following conclusions can be drawn: 222 papers are cited. Among them, there were 59 papers, and there were 39 papers cited twice, 34 papers were cited three times, 24 papers were cited 4 times, 11 papers were cited 5 times, 6 times There are 15 , cited 8 times 8 , cited 8 times 6 , cited 9 times 4 , cited 10 times 6 , cited 11 times there are 2 , Cited 12 times there are 4 , cited 13 times and more than 10 , see Table 6 .

As can be seen from Table 6, Li Guiyuan's "English and Chinese taboo and euphemism" cited the highest frequency, cited frequency nearly twice the second. This paper considers the following two reasons: First, the article involves the English and Chinese languages; Second, the text involves euphemism and taboo. These two reasons is the current scholars to write taboo related research important point, so cited the highest frequency.

In fact, from the ten cited cited the highest papers can also see these two reasons. There are five English and Chinese languages, there are five articles related to taboo and euphemism.

Table 6. Papers cited 13 times and above the situation statistics.

\begin{tabular}{lll}
\hline Cited author & Cited title & Cited frequency \\
\hline Li Guiyuan & On the Taboo and Euphemism in English and Chinese \\
Zhang ying & A Contrastive Analysis of Taboo in Chinese and English \\
Ma Weilin & On the Function of Taboo Language \\
Lu Jie & Differences of Taboos between China and the West from Intercultural Communication \\
Wang Weizhen; Xu Pingfei & Taboo in Japanese and Its Latest Development \\
Li Xianjin & Cultural Connotation and Contrast of Taboo in English and Chinese \\
Yan Li Fen & A Comparative Study of Taboo and Euphemism Differences between Chinese and Western \\
Liu Yuelian & A Study on Family Similarity of Euphemism and Taboo \\
Liu Qingbo & Taboo, taboo, euphemism \\
Yuan Xiufeng & A Probe into the Fundamental Psychological Mechanism of the Presence of Death and Language - \\
\hline
\end{tabular}

\section{An Analysis of the Subject and Content}

Since the 21 st century, the paper on the study of taboo in China has certainly regarded Chinese as the main research object. However, since the previous period has been countless to the study of taboo in Chinese, See, in this 387 papers in 8 . This period is more of a specific Chinese phenomenon in the taboo language to study, and these specific Chinese phenomenon more to bring the color of the times. [7] According to the statistics of the 387 papers, the following aspects are as follows: women taboo, drug instruction taboo, shopping ban taboo, trademark taboo, entertainment taboo, cadre taboo, death taboo, digital taboo, hotel service taboo, Banned taboos, prohibition of taboos, greetings taboo, news taboos, kinship taboos, hostage hijacking in the police commonly used taboo, cell phone taboo, classroom taboo, erotic taboos, gestures taboo and so on.

The theme and content distribution of the paper on taboo research in our country are not balanced. The research mainly focuses on the cross-cultural communication research of taboo and the combination of taboos and euphemism. The proportion of the other aspects is relatively small some.

(1) There are 93 papers in the theoretical study of taboo language, reaching $24.04 \%$ of the total number of papers, which reflects that Chinese scholars pay more attention to the research of basic knowledge, which is consistent with the tradition of academic theory in China.

In this category, there are $33.33 \%$ and $26.88 \%$ of the papers on the pragmatic studies of tabuos and the cultural factors of taboo, which reflect the proportion of Chinese scholars in this stage. Focus on these two areas. Other aspects of the theoretical study of taboo language research has long been studied very early, there is no innovation, so the relevant papers will be very few. And pragmatics and culture in the 21 st century has continued to increase heat, naturally from 
these two angles to study the taboo will be more. [8] It is necessary to mention that the cultural factors of taboo language also include many angles. In these 25 papers, there are cultural differences, cultural background, cultural background, cultural comparison, cultural connotation and so on.

This taboo function and function of the taboo is also quite innovative, which refers to the taboo of the communication function and social function.

(2) taboo practice and research papers have 7, it can be said that so far our country on the taboo of empirical research is still rare. For example, Jiao Yalu investigated the frequency of the use of taboo in Chinese and American Americans who were educated and age. Liang Hongmei made a presentation on the "taboo topic" in a pragmatic questionnaire for English native speakers. Analysis; Wu Risheng and other students in the school with a taboo on the attitude of mobile phone messages and so on.

(3) The study of cross-cultural communication in taboo language is the focus of the taboos study in this period. There are 240 papers, reaching $62.02 \%$ of the total number of papers, which is related to the new era of global integration and the characteristics of Chinese international promotion Demand is inextricably linked. Intercultural communication is not only a young discipline, but also a comprehensive discipline. [9] It is the result of the comprehensive study of contemporary social science. The subject background mainly deals with cultural linguistics, sociolinguistics and verbal communication. So the researchers will naturally study the perspective of this aspect tilt.

One of the most prominent is the comparative study, there are 194 papers, accounting for $80.83 \%$ of the total number of papers. The comparative study of cross-cultural communication mainly involves the comparison of taboos between different languages, so as to better grasp the cultural connotation of taboo between different languages and also have some helpful help to translation and teaching. Specifically related to the language contrast in Table 7 has been clearly reflected, here is no longer discussed.

Translation studies mainly suggest that some tabuos translation methods, such as domestication and alienation, literal translation and paraphrase. Teaching research mainly for the second language teaching, some error analysis or put forward some teaching strategies. And comprehensive research is the above three aspects of comprehensive discussion.

(4) There are many papers on the combination of taboo and euphemism, accounting for $16.54 \%$ of the total number of papers, because there is a great connection between the two.

In real life, people try to avoid using taboo. However, in many cases they have to talk about those sensitive aspects, so in order to meet the needs of communication and not guilty, people will use the implicit twists and turns, beat the way to speak out, which formed a euphemism. [10] Can be said that euphemism and taboo is a coin on both sides: different and worth the same. So now there are many researchers to combine the two to study one of the problems, the specific research point of view and Table 8 taboo research point of view is not different.

(5) taboos interdisciplinary research is rare, there are 17 , accounting for $4.39 \%$ of the total number of papers. When it comes to taboo, people always think from the perspective of social linguistics or cultural linguistics, in fact, it can also be other disciplines on the analysis.

In the cognitive linguistics, there are archetypal theory and metaphor theory to analyze the taboo language; in psychology, mainly to analyze the psychological characteristics of taboo; in anthropology, only a paper mainly Explores the relationship between the evolution of taboo and mankind.

\section{Conclusion}

Taboo language as part of the human language, the world is a common cultural phenomenon of all ethnic groups in life is inevitable. With the development of social culture and the increasingly frequent intercultural communication activities, it is of great significance to explore the new development and new trends of taboo.

Since the 21 st century, Chinese scholars have published a large number of academic papers on taboo research, researchers from different research perspective on the taboo language were discussed. However, our research on taboo is not perfect, there are many issues worthy of our further exploration. Therefore, the future of China's taboo language research proposed the following recommendations:

(1) Among the many studies on taboo, there are few qualitative studies in China, and quantitative research is rare, and quantitative research only involves questionnaire survey. Therefore, it is necessary to introduce foreign advanced research methods, such as corpus language method.

(2) Chinese scholars on the taboo of the study are mostly to adopt a "point to the end" attitude and practice. Therefore, it is necessary to conduct empirical research and case studies on specific taboo themes or phenomena.

(3) the taboos and cognitive linguistics, psychology, anthropology and other disciplines of the combination of research is still very little, it is necessary to taboo and speech taboo phenomenon for more perspective, more disciplines of the study, contrast With the examination.

(4) taboo language from the community, with the continuous development of the times, taboo is also developing. There are still many questions to be discussed about the changes in taboos and the social factors that affect the development of taboo.

(5) In the treatment of taboo translation, there is no more consistent view of the academic community, are some non-uniform translation methods, it is necessary in the translation of innovative research, and strive to meet the cultural tradition between the two languages The

(6) For foreign language teaching teachers and learners on the taboo should be what kind of attitude in the teaching of all aspects of teaching materials, teachers, classroom teaching how to show the phenomenon of taboo, teachers should take what strategy to improve Foreign language 
learners on the use of taboo language awareness and other issues remain to be studied.

\section{References}

[1] Zhang Airong. A review of English and Chinese taboos at home and abroad. Journal of Hunan Medical University .2010 (5).

[2] Ding Qihong. Electronic linguistics of euphemism and taboos. Overseas English .2013 (4).

[3] Shen Qin, Li Gang, Mi Haiyan. Literature Review of Chinese Idioms Culture. Journal of Changzhou Institute of Technology. 2011 (3).

[4] Chen Zhiping. Cultural Differences between Chinese and English Taboos and Teaching Chinese as a Second Language. Jiangsu: Suzhou University, 2014.
[5] Yang Hongwei. Comparative study of English and Chinese euphemisms Guangxi: Guangxi Normal University, 2001.

[6] Ou Yamei, Li Jing. Talk about the taboo translation. Journal of Hunan Medical University .2008 (1).

[7] Li Guiyuan. Discussion on English and Chinese Taboos and Euphemism. Journal of Tianjin Foreign Studies University. 2004 (5).

[8] Zhao Yao. A comprehensive analysis of taboo social interpersonal [D]. Beihua University, 2007.

[9] Jiang Zhiwei. Taboo language cultural connotation and translation $[\mathrm{J}]$. China Science and Technology Translation, 2006, (04).

[10] Ma Weilin. Analysis of the social factors influencing the development of taboo [J]. Journal of Beijing Second International Studies University, 2001, (06). 